\title{
PREVALENCE, PATHOGENICITY AND ANTIBIOGRAM SENSITIVITY OF PSEUDOMONAS AERUGINOSA ISOLATED FROM DISEASED CHICKENS
}

\author{
HEBA BADR; HEBA ROSHDY; ABD EL-HAFEZ S. ABD EL-HAFEZ and \\ EMAN M. FARGHALY
}

Reference Laboratory for Veterinary Quality Control on Poultry Production, Animal Health Research Institute, Ministry of Agriculture, Nadi El-Seid Street, Dokki P.O. Box246, Giza 12618, Egypt.

Received: 1 September 2016; $\quad$ Accepted: 31 October 2016

\begin{abstract}
Pseudomonas aeruginosa is an opportunistic pathogen which produces several diseases and considered all over the world as one of the most dangerous diseases which affect animals. A total of thirteen isolates were identified as $P$. aeruginosa with percentage of $6.5 \%, 7.3 \%$ from diseased and dead chicken and $4 \%$ from one day old chicks. Polymerase chain reaction (PCR) for detection of oprL gene of P. aeruginosa was applied and showed positive amplification of $504 \mathrm{pb}$ fragments. The isolates were found to be resistant for Neomycin, Nalidixic acid and Lincomycin followed by Trimethoprim-sulfamethoxazole, Chloramphenicol then Tetracycline and Doxycyclin but appeared sensitive to Levofloxacin with percentage of 100\%, $92.3 \%$ to Norfloxacin, $84.6 \%$ to Ciprofloxacin, $77 \%$ to both Colistin sulphate and Gentamicin but $61.5 \%$ to streptomycin. In experimental infection for all isolated strains via yolk sac in 7 days SPF eggs and via subcutaneous injection in 3 days old chicks which expressed the virulence of these strains by its high mortality rate which reached 100\% within 24-72 hrs.
\end{abstract}

Key words: Pseudomonas aeruginosa, poultry, antibiogram, Pathogenicity.

\section{INTRODUCTION}

Pseudomonas aeruginosa is one of the species belonging to genus Pseudomonads which included in Pseudomonaceae family. It is gram negative bacteria, moving with polar flagella and produces various fluorescent pigments (Tamer et al., 1989).

$P$. aeruginosa is the representative of the genus with the highest importance in avian pathology (Fodor, 2007). It is ubiquitous and often found in soil, drinking water, and humid environments (Mohamed, 2004; Mena and Gerba, 2009). The infection may occur through skin wounds or contaminated vaccines, morbidity and mortality due to Pseudomoniasis ranged between 2 to $100 \%$, but more commonly about $2-12 \%$ with greatest losses in very young birds (John Barnes, 1997). The mortality rate by $P$. aeruginosa is higher than other gram negative pathogens because it has ability to produce several extracellular products that after colonization can cause extensive tissue damage and invaded blood and

Corresponding author: Dr. HEBA BADR

E-mail address: drheba_badr@yahoo.com

Present address: Reference Laboratory for Veterinary Quality Control on Poultry Production, Animal Health Research Institute, Ministry of Agriculture, Nadi El-Seid Street, Dokki P.O. Box246, Giza 12618, Egypt. dissemination. Among these extracellular products are alkaline protease, elastase, haemolysins, phospholipase "C". Thus virulence of this organism appears multifactorial, its cellular products and extracellular products ensure its ability to infect most hosts (Herbert, 2003 and Ali et al., 2009). In experimental trial, P. aeruginosa was found to be highly virulent to the young chickens (1 - 10 day old) and less virulent to chickens of 11 - 20 days, while older chickens (>20 days) were found to be resistant to the infection (Kebede, 2010). Naturally $P$. aeruginosa is resistant to many widely used antibiotics which resulted from an impermeable outer membrane and the production of extracellular polysaccharides (Quinn, 1992). Some authors reported that the pathogenicity of $P$. aeruginosa in poultry was associated with septicemic and respiratory infections, sinusitis, keratitis, keratoconjunctivitis, and high embryonic death in hatcheries (Hartl et al., 1997; Hussein et al., 2008 and Hai-ping, 2009). Many researchers have made attempts to develop molecular methods especially PCR for the detection of $P$. aeruginosa (Nikbin et al., 2012). $P$. aeruginosa was detected using sequencespecific target; the outer membrane protein $(O p r \mathrm{~L})$ gene locus (Abdullahi et al., 2013). This study was conducted to isolate $P$. aeruginosa from diseased chickens and apparently healthy chicks, to investigate the presence of organism in chicken and determine 
the phenotypic and genotypic character of isolates then detection of its pathogenicity in vivo in chicken embryos and one day old chicks.

\section{MATERIALS AND METHODS}

\section{1-Sample collection:}

A total of 200 samples (150 samples collected from diseased and dead chicken and 50 yolk samples of apparently healthy one day old chicks) were examined. Collected samples included tracheal and cloacal swabs from diseased chickens and internal organs (heart, liver, lungs, intestine and/or bone marrow) from freshly dead one, in addition to the yolk sacs of one day old chicks. All samples used were collected under aseptic conditions and safety precautions to prevent cross contamination according to (Middleton et al., 2005) as in Table (1). The examined samples from farms of different Governorates of Egypt were submitted to the Reference laboratory for veterinary quality control on poultry production (RLQP).

Table 1: Sources and numbers of examined samples.

\begin{tabular}{cccc}
\hline \multicolumn{2}{c}{ Type of samples } & & No. of samples \\
\hline Tracheal swabs & Diseased chicken & 50 \\
\hline Cloacal swabs & freshly dead & 100 \\
\hline Intestine & & & \\
\hline Bone marrow & & & 50 \\
\hline Lung & & One day old chicks & $\mathbf{2 0 0}$ flocks \\
\hline Liver & Total & & \\
\hline Holk sac & & & \\
\hline
\end{tabular}

\section{2- Bacterial Isolation:}

Bacteriological examination of 200 chicken samples was done according to Shukla and Mishra, (2015). The samples were collected from internal organs (heart, liver, spleen, and bone marrow) of 150 diseased and dead chicken that showed sever congestion in the internal organs, turbidity in the pericardium, pneumonic lungs and 50 yolk sac from apparently healthy newly-hatched chicks. The samples were inoculated in buffered pepton water and incubated aerobically for 24 hours at $37^{\circ} \mathrm{C}$. A loopfull of inoculated broth was streaked onto different selective media (pseudomonas agar, Trypticase soya agar and MacConkey agar) and incubated aerobically for $24-48$ hours at $37^{\circ} \mathrm{C}$; pigment production and lactose fermentation were detected respectively. The plates containing characteristic colonies of $P$. aeruginosa (large, irregular, translucent and produced a greenish diffusible pigment and characterized by its fruity smell) were selected and the Gram staining test was performed then subjected to biochemical identification according to (Buxton and Fraser 1977). API 20 was used as a confirmatory biochemical test. Bacterial isolates were confirmed by the api $20 \mathrm{E}$ identification system (BioMérieux ${ }^{\circledR}$, France).

\section{3- Antimicrobial sensitivity test:}

The antibiogram of $P$. aeruginosa isolates were done by disc-diffusion test according to Koneman et al. (1997) against 13 antibiotics (Oxoid) and interpretation according to the Clinical and Laboratory Standards Institute/ Formerly National Committee for Clinical Laboratory Standard CLSI/NCCLS, (2009) as shown in Table (2). 
Table 2: The interpretation of Ps. aeruginosa sensitivity test according to (CLSI/NCCLS, 2009).

\begin{tabular}{|c|c|c|c|c|c|}
\hline \multirow{3}{*}{$\begin{array}{l}\text { Antimicrobial } \\
\text { Discs }\end{array}$} & \multirow{3}{*}{ Code } & \multirow{3}{*}{$\begin{array}{c}\text { Disc } \\
\text { Potency } \\
\text { Mg/disc }\end{array}$} & \multicolumn{3}{|c|}{ Interpretation } \\
\hline & & & \multicolumn{3}{|c|}{ Zone diameter (mm) } \\
\hline & & & $\begin{array}{c}\text { Sensitive } \\
\geq\end{array}$ & Intermediate & $\begin{array}{c}\text { Resistant } \\
\leq\end{array}$ \\
\hline Colistin sulphate & $\mathrm{CT}^{10}$ & $10 \mu \mathrm{g}$ & 11 & $\longrightarrow$ & 10 \\
\hline Chloramphenicol & $\mathrm{C}^{30}$ & $30 \mu \mathrm{g}$ & 18 & $13-17$ & 12 \\
\hline Ciprofloxacin & $\mathrm{Cip}^{5}$ & $5 \mu \mathrm{g}$ & 21 & $16-20$ & 15 \\
\hline Doxycyclin & $\mathrm{Do}^{30}$ & $30 \mu \mathrm{g}$ & 16 & $13-15$ & 12 \\
\hline Gentamicin & $\mathrm{G}^{10}$ & $10 \mu \mathrm{g}$ & 15 & $13-14$ & 12 \\
\hline Levofloxacin & Lev $^{5}$ & $5 \mu \mathrm{g}$ & 17 & $14-16$ & 13 \\
\hline Lincomycin & $\mathrm{L}^{2}$ & $2 \mu \mathrm{g}$ & 18 & $15-17$ & 14 \\
\hline Nalidixic acid & $\mathrm{NA}^{30}$ & $30 \mu \mathrm{g}$ & 19 & $14-18$ & 13 \\
\hline Neomycin & $\mathrm{N}^{30}$ & $30 \mu \mathrm{g}$ & 17 & $15-16$ & 14 \\
\hline Norfloxacin & $\mathrm{NX}^{10}$ & $10 \mu \mathrm{g}$ & 17 & $13-16$ & 12 \\
\hline Streptomycin & $\mathrm{S}^{10}$ & $10 \mu \mathrm{g}$ & 15 & $12-14$ & 11 \\
\hline $\begin{array}{l}\text { Trimethoprim- } \\
\text { sulfamethoxazole }\end{array}$ & SXT & $\begin{array}{c}1.25- \\
23.75 \mu \mathrm{g}\end{array}$ & 16 & $11-15$ & 10 \\
\hline Tetracyclin & $\mathrm{T}^{30}$ & $30 \mu \mathrm{g}$ & 15 & $12-14$ & 11 \\
\hline
\end{tabular}

\section{4- Molecular identification:}

Conventional PCR Assay for confirmation of Pseudomonas aeruginosa isolates. DNA was extracted from isolates by QIAamp DNA Mini Kit, (Qiagen, Germany, GmbH) Catalogue no.51304. PCR were performed on extracted DNA by using specific primer to oprL gene (Metabion, Germany) were amplified according to references mentioned in Table (3). Primer were utilized in a 25- $\mu$ l reaction containing $12.5 \mu \mathrm{l}$ of Emerald Amp Max PCR Master Mix (Takara, Japan), $1 \mu \mathrm{l}$ of each primer of 20 pmol concentrations, $4.5 \mu \mathrm{l}$ of water, and $6 \mu \mathrm{l}$ of template.
The reactions were performed in a Biometra $\mathrm{T} 3$ thermal cycler. The product of PCR was separated by electrophoresis on $1 \%$ agarose gel (Applichem, Germany) in $1 \mathrm{x}$ TBE buffer at room temperature using gradients of $5 \mathrm{~V} / \mathrm{cm}$. For gel analysis, $15 \mu \mathrm{l}$ of the products was loaded in each gel slot. A $100 \mathrm{bp}$ DNA Ladder (Qiagen, Germany, GmbH) was used to determine the fragment sizes. The gel was photographed by a gel documentation system (Alpha Innotech, Biometra) and the data was analyzed through computer software.

Table 3: Oligonucleotide primers sequence encoding to oprL gene for $P$. aeruginosa and the size of amplified products required for detecting the tested gene.

\begin{tabular}{cccc}
\hline $\begin{array}{c}\text { Target } \\
\text { gene }\end{array}$ & \multicolumn{1}{c}{ Primer sequence (5'-3') } & $\begin{array}{c}\text { Amplicon } \\
(\mathbf{b p})\end{array}$ & References \\
\hline oprL & $\begin{array}{l}\text { F: ATG GAA ATG CTG AAA TTC GGC } \\
\text { R: CTT CTT CAG CTC GAC GCG ACG }\end{array}$ & 504 bp & (Xu et al., 2004) \\
& & & \\
\hline
\end{tabular}

\section{5- Pathogenicity tests:}

A- Chicken embryo: one hundred and forty five, 7 days old fertilized SPF eggs were used, five from them taken at random and examined bacteriologically to ensure that they were Pseudomonas free. The one hundred and forty eggs were divided into 14 groups: each of the first thirteen groups consisting of ten eggs were inoculated via yolk sac route by $0.1 \mathrm{ml}$ of 24 hour broth culture contain $14 \times 10^{7}$ viable cell of $P . / \mathrm{ml}$ (Saad et al., 1981), while The last group consisting of ten eggs were kept as negative control.
B- Chicks: one hundred and forty five, 3- days-old chicks were divided into 14 groups as follow: thirteen infected groups (ten chicks per group) were inoculated subcutaneously $0.1 \mathrm{ml}$ of 24 hour broth culture of the isolated organism and one group (ten chicks) as control negative while five chicks taken at random a day before infection and examined bacteriologically to ensure that they were $P$. free (Awaad et al., 1981). Birds were fed rations of antibiotic-free and supplied with water adlibitum with 24 hours of light daily. 


\section{RESULTS}

Clinically diseased cases showed respiratory distress and some cases showed diarrhea in addition to mortality. Postmortem examination of the dead birds showed septacimea, fibrinous pericarditis, perihepatitis, airsaculitis and some cases showed enteritis. In the present study bacteriological examination of the 200 collected samples revealed that 13 samples were positive for $P$. aeruginosa with a percentage of $6.5 \%$ after confirmed of 18 suspected isolates by api 20E (Table, 4 and Fig.1). Out of 150 samples from diseased and dead chicken, 11 samples with a percentage of $7.3 \%(11 / 150)$ were positive for $P$. aeruginosa and $4 \%$ (2/50) from one day old chicks.

In our study the conventional PCR for oprL gene which had done from the enriched isolated strains revealed that all the isolates were confirmed by the polymerase chain reaction (Fig. 2).

Table 4: Incidence of $P$. aeruginosa.

Sources of samples
No.

No. of positive samples
$\%^{*}$

\begin{tabular}{cccccc}
\hline Diseased chicken & 50 & 2 & \multirow{2}{*}{7} & 7.3 \\
\hline Freshly dead chicken & 100 & 9 & & \\
\hline One day old chicks & 50 & & 2 & 4 \\
\hline Total & 200 & & 13 & $6.5^{* *}$ \\
\hline
\end{tabular}

*Percentage according to total number of each source of sample.

** Percentage according to total number of the samples.

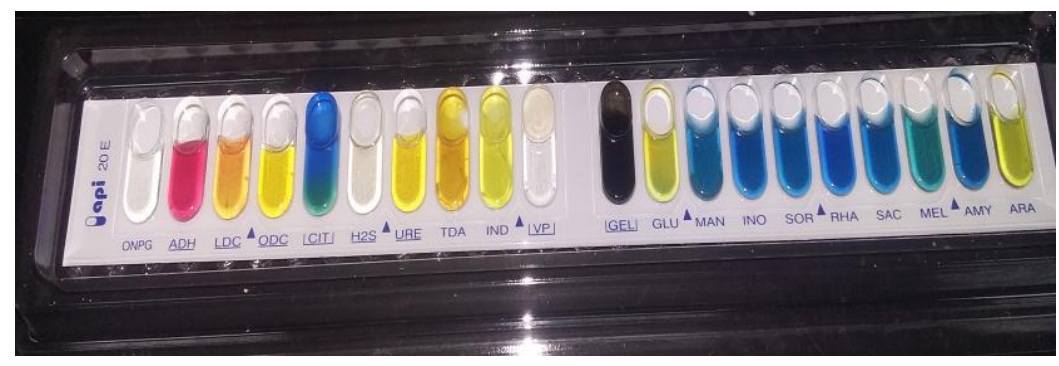

Fig. (1): Api 20E strip show positive P. aeruginosa with identification number 2202000.

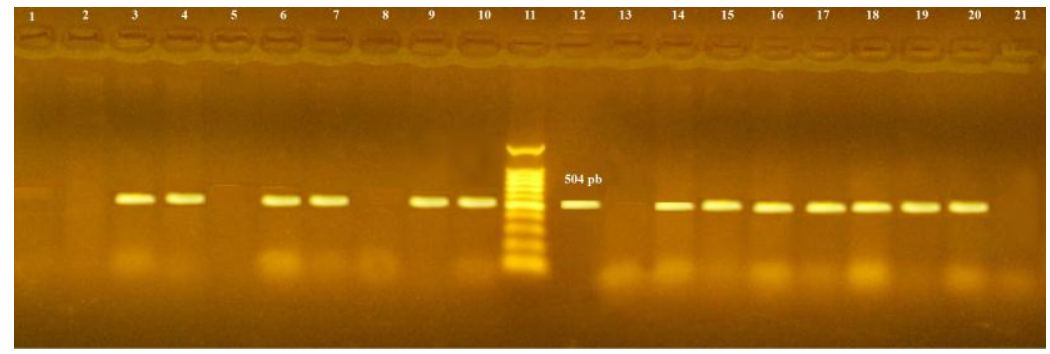

Fig. (2): Amplification of the oprL gene of P. aeruginosa for the 18 isolates, positive amplification appeared at 504bp lane 21 negative control, lane 12 the positive control (ATCC 9027) and lane 11 the ladder 100+ (Qiagen) .

In the present study, as shown in Table (5) antimicrobial sensitivity test of $13 P$. aeruginosa isolates showed high resistance $(100 \%)$ to Neomycin, Nalidixic acid and Lincomycin followed by Trimethoprim-sulfamethoxazole, Chloramphenicol then Tetracyclin and Doxycyclin. While high sensitivity percentage $100 \%$ to Levofloxacin, $92.3 \%$ to Norfloxacin, $84.6 \%$ to Ciprofloxacin, $77 \%$ to Colistin sulphate and Gentamicin but $61.5 \%$ to streptomycin. 
Table 5: Results of antimicrobial sensitivity tests.

\begin{tabular}{cccc}
\hline \multirow{2}{*}{ Antimicrobial discs } & \multicolumn{2}{c}{$\boldsymbol{P}$ aeruginosa isolates Interpretation (No.= 13) } \\
\cline { 2 - 4 } & Sensitivity $(\boldsymbol{\%})$ & $\begin{array}{c}\text { Intermediate } \\
(\boldsymbol{\%})\end{array}$ & Resistance (\%) \\
\hline Colistin sulphate & $10(77 \%)$ & 0 & $3(23 \%)$ \\
\hline Chloramphenicol & $1(7.7 \%)$ & $5(38.5 \%)$ & $7(53.8 \%)$ \\
\hline Ciprofloxacin & $11(84.6 \%)$ & $1(7.7 \%)$ & $1(7.7 \%)$ \\
\hline Doxycycline & $4(30.75 \%)$ & $4(30.75 \%)$ & $5(38.5 \%)$ \\
\hline Gentamicin & $10(77 \%)$ & 0 & $3(23 \%)$ \\
\hline Levofloxacine & $13(100 \%)$ & 0 & 0 \\
\hline Lincomycine & 0 & 0 & $13(100 \%)$ \\
\hline Nalidixic acid & 0 & 0 & $13(100 \%)$ \\
\hline Neomycin & 0 & 0 & $13(100 \%)$ \\
\hline Norfloxacin & $12(92.3 \%)$ & $1(7.7 \%)$ & 0 \\
\hline Streptomycin & $8(61.5 \%)$ & 0 & $5(38.5 \%)$ \\
\hline Tetracycline & $2(15.4 \%)$ & 0 & $11(84.6 \%)$ \\
\hline Trimethoprim-sulfamethoxazole & $3(23 \%)$ & $5(38.5 \%)$ & $5(38.5 \%)$ \\
\hline
\end{tabular}

In the present investigation pathogenicity tests revealed that the chicken embryos showing $100 \%$ mortality between 2-3 days post- inoculation with formation of caseated material and congestion but in the chicks some groups developed clinical signs after 24-72 hour post-inoculation (P-I) they showed sleepy appearance, closed eyes, sitting on hocks, some birds laid on one side and exhibited convulsions in the legs and head and diarrhoea. The mortality rate reached to $100 \%$ in two groups within 24 hour (P-I), $80 \%$ in four groups within $72 \mathrm{hrs}, 60 \%$ mortality in four groups within $72 \mathrm{hrs}$ and one group showed $40 \%$ mortality within 72 hrs. While, only one group did not show any mortality rate. Gross lesions revealed sever general congestion of the carcasses combined with haemorrhage in body cavity, peticheal haemorrhages on liver and spleen with congestion of them and pericarditis, lungs were pneumonic, congestion and swollen of kidneys with deposition of ureats in the urters. Also enteritis, enlargement of the gall-bladder, congestion of thigh muscle, caseated material in the abdominal cavity and unabsorbed congested yolk sacs were present. Control group showed no clinical signs or lesions.

\section{DISCUSSION}

Pseudomonas infections of birds are of great importance because epidemics may spread rapidly through poultry flocks causing mortality in all ages Shukla and Mishra (2015). Pseudomonas aeruginosa has been isolated from chicks with omphalitis and is mentioned as an opportunistic pathogen that is able to produce a localized or systemic disease in newly hatched chicks. The ability of Pseudomonas spp. to cause infection of yolk sac of a chick is enhanced by its ability to degrade the proteins found in the yolk, providing the opportunity for other bacteria to multiply (Walker et al., 2002). In the present study bacteriological examination of the 200 collected samples revealed that 13 samples were positive for $P$. aeruginosa with a percentage of $6.5 \%$ and confirmed the isolation by api 20E. Out of 150 samples from diseased and dead chicken, 11 samples with a percentage of $7.3 \%(11 / 150)$ were positive for $P$. aeruginosa and 4\% (2/50) from one day old chicks. These results agreed to great extend to that obtained by many author as Choudhury et al. (1993) who isolated $P$. aeruginosa in a percentage of $4.75 \%$, Younes et al. (1990) who isolated P. aeruginosa from 20 dead chickens with percentage of $4.9 \%$. Chakrabarty et al. (1980) isolated P. aeruginosa with incidence of $8 \%$ from 100 chicken suffering from respiratory symptoms while Awaad et al. (1981) isolated $P$. aeruginosa with an incidence of $2.9 \%$ from an outbreak in a broiler flock. Similar results were reported by Mrden et al. (1988) who recovered $P$. aeruginosa from dead broiler with an incidence of $3.6 \%$. Also Mohamed, (2004) recorded that $P$. aeruginosa was found in $3.3 \%$ of examined diseased and dead broilers while in baby chicks $P$. aeruginosa was isolated from 17.6\%. Al-Adl, (2014) isolated seventeen isolates of P.aeruginosa (4.57\%) from diseased, dead and apparently healthy at different ages of broiler chicken. Hussein et al. (2008) tested 140 diseased or dead broiler chicks (yolk sac samples) and found $P$. aureuginosa at 5 samples with percentage $2.6 \%$. On the other hands, reported that the organism was isolated at the rate of $20 \%$ at kena Governorate by El-Bakry, (1983) and Hassan, (2013). Shukla and Mishra (2015) isolated P. aeruginosa from apparently healthy and clinically diseased broilers with percentage of $12 \%$ and $30 \%$ respectively. The conventional PCR for oprL gene which had done from the enriched isolated strains revealed that all the isolates were confirmed by the polymerase chain reaction. These results are in correlated with Malorny et al., 2003 who mentioned that in vitro amplification of DNA by PCR method is a powerful tool in microbiological diagnostics. Also, many authors as (Achtman et al., 1986; Caugant et al., 1985; Whittam and Wilson, 1988) reported that 
the application of PCR as an additional diagnostic tool is even more important in light of the fact, that the designation of a serogroup does not reflect the virulence of that strain.

The results of antimicrobial sensitivity test of $13 P$. aeruginosa isolates showed high resistance (100\%) to Neomycin, Nalidixic acid and Lincomycin followed by Trimethoprim-sulfamethoxazole, Chloramphenicol then Tetracyclin and Doxycyclin. While high sensitivity percentage $100 \%$ to Levofloxacin, $92.3 \%$ to Norfloxacin, $84.6 \%$ to Ciprofloxacin, $77 \%$ to Colistin sulphate and Gentamicin but $61.5 \%$ to streptomycin. Al-Adl, (2014) reported that $P$. aeruginosa isolates were highly sensitive to Colstin sulphate $(76.5 \%)$ and Norfloxacin $(52.9 \%)$ while Gentamicin and Ciprofloxacin gave $23.5 \%$ and $17.6 \%$ respectively, while resistant to lincomycin, Naldixic acid, Streptomycin, Chloramphenicol and Doxycyclin. Kim et al. (1982) mentioned that all strains of $P$. aeruginosa were susceptible to Gentamicin and Colistin. Also, Walker et al. (2002) showed that the isolates were resistant to lincomycin, naladixic acid, and tetracycline with varied in sensitivity to other antibiotics, but all isolates were sensitive to gentamicin, Mohamed, (2004) showed that the isolated $P$. aeruginosa was highly sensitive to the norfloxacin, chloramphenicol and streptomycin but moderate sensitive to Gentamicin. Moreover, Abd El-Gawad et al. (1998) reported that $P$. aeruginosa isolates from chickens were highly sensitive to Neomycin, Colistin and Tetracyclin.

In the present investigation pathogenicity tests correlated to that obtained by Mohamed, (2004) who conducted the experimental infection in eggs by isolated $P$. aeruginosa; showed deaths of all embryos inoculated via yolk sac route, $80 \%$ mortality of 3days old chicks' inoculated subcutaneously and appeared the same clinical signs and gross lesions as our study. Similar to that reported by Awaad et al. (1981) who recorded $100 \%$ mortality to the inoculated chicks. Also, Abd-EL Gwad et al. (1998) stated that the experimental infection in 3-day old chicks by subcutaneous route inoculation was highly effective with mortality rate $95 \%$ and the gross lesions of inoculated birds showed congested liver, spleen and kidneys. Al-Adl (2014) Showed 100\% mortality rate in the two groups inoculated with $P$. aeruginosa isolates within time 24 to $48 \mathrm{hrs}$. and stated the same clinical and gross lesion as our result. While, Walker et al. (2002) induced five isolates of $P$. aeruginosa by inoculated it in five groups of 10 One-day-old chicks via yolk sac. Virulence varied greatly among the isolates, resulting in mortality rates from 0 to $90 \%$. The challenge isolates produced different and often distinctive postmortem lesion patterns.

\section{CONCLUSION}

Our results focusing on the $P$. aeruginosa infection present in the chicken farms and study the Pathogenicity of this isolates in chicken embryos and baby chicks so good hygiene measures especially in hatcheries is fundamental for Pseudomonas control. Also the use of suitable antibiotic in the day old chicks could help in reduce flock mortality. A strict antibiotic policy and establishment of infection control programs will help to lower the incidence of resistance in $P$. aureginosa.

\section{REFERENCES}

Abd El-Gawad, A.M.; Ali, S.M. and Azzaz, H.A. (1998): Some studies on pseudomonas aeruginosa infection in growing chickens in assiut farm. Assuit J. Vet. Med., 38 (76): 9097.

Abdullahi, R.; Lihan, S.; Carlos, B.S.; Bilung, M.L.; Mikal, M.K; and Collick, F. (2013): Detection of oprL gene and antibiotic resistance of Pseudomonas aeruginosa from aquaculture environment. European Journal of Experimental Biology., 3(6): 148-152.

Achtman, M.; Heuzenroder, M.; Kusecek, B.; Ochman, H.; Selander, R.K.; Vaisanen-Rhen, V.; Korhonen, T.K.; Stuart, S. and Orskov, F. (1986): Clonal analysis of Escherichia coli $\mathrm{O} 2: \mathrm{k} 1$ isolated from diseased humans and animals. Infect. Immune. 51: 268-279.

Al-Adl, M.M. (2014): some bacteriological studies on Pseudomonas aeruginosa in poultry. M. V. Sc. Thesis (Microbiology), Fac. Vet. Med. Benha Univ.

Ali, M.; Jamshid, K.; Davood, M.; Aziz, J.; Masoud, A.; Mohsen, N.; Ahmed, H.Z. and Nazanin, K. (2009): Active immunization using exotoxin A confers protection against Pseudomonas aeruginosa infection in a mouse bum model. BMC Microbial., 9-23.

Awaad, M.H.; Youssef, V.I.; Saad, F.E. and Sarakbi, T.M.B. (1981): Study on P. aeruginose in chickens. Vet. Med. J. of Cairo Univer., 29: 135-143.

Buxton, A. and fraser, G. (1977): pseudomonas: Animal Microbiology, 1: 241. Oxford: Blackwell.

Caugant, D.A.; Levin, B.R.; Orskov, F.; Svanborg Eden, C.; Selander, R.K. (1985): Genetic diversity in relation to serotype in Escherichia coli. Infect. Immune. 49, 407-413.

Chakrabarty, A. K.; Boro, B. R.; Sarmah, A. K. and Sarma, G. (1980): Antimicrobial sensitivity of Pseudomonas aeruginosa isolated from animals and birds. Livestock Adviser India., 5 (8): 44- 46.

Choudhury, B.; Chanda, A.; Dasgupta, P.; Dutta, R.K.; Lila Saha and Sanatan Bhuin (1993): Studies on yolk sac infection in poultry, 
antibiogram of isolates and correlation between in-vitro and in-vivo drug action. Indian J. of Animal Health. 32(1): 21-23.

CLSI/NCClS (2009): Performance Standards for Antimicrobial Disk Susceptibility Tests, Approval Standard-Tenth Edition and Performance Standards for Antimicrobial Susceptibility Test, M02-A10 and M100-S20.

El-Bakry, S.M. (1983): Some studies on Pseudomonas infection in chickens. M. V. Sc., Thesis Presented to Fac. of Vet. Med., Assiut Univ.

Fodor, I. (2007): Observation upon the development of a pseudomonosis episode in broiler farm. Lucrari Stiinifice Med Vet, XL: 375-378.

Hai-ping, H.E. (2009): Isolation and identify of Pseudomonas aeruginosa in chicken deadembryos. Chinese Qinghai J Anim Vet Sci, 3: 25-27.

Hartl, A.; Mollmann, U.; Schrinner, E. and Stelzner, A. (1997): Pseudomonas aeruginosa infection in embryonated heh's eggs. An alternative in vivo model for the screening of antibacterial substances. Arzneimittelforschung, 47: 10611064.

Hassan, H.M. (2013): Characterization of Pseudomonas aeruginosa isolated from different pathological lesions in chickens. M. V. Sc. Thesis (Microbiology), Fac. Vet. Med. Beni-Suef Univ.

Herbert, P.S. (2003): Mechanism of resistance to antimicrobials in Pseudomonas aeruginosa and related bacteria. Genet Mol Res 2: 1. 4862.

Hussein, S.A.; Hassan, A.H. and Sulaiman, R.R. (2008): Bacteriological and pathological study of yolk sac infection in broiler chicks in sulaimani district. J Dohuk Univ, 11(1): 48-56.

John Barnes, H. (1997): Other bacterial diseaes: Pseudomonas. In Diseases of Poultry, edited by Calnek, B. W., John Barnes, H., Beard, C.W., Mcdougald L.R. and Saif, Y. M., 10 th edition P. $291-292$.

Kebede, F. (2010): Pseudomonas infection in chickens. Journal of Veterinary Medicine and Animal Health, 2(4):55-58.

Kim, K.S.; Namgoong, S.; MO, I.P. and Park, K.S. (1982): Biochemical and drug susceptibility tests of pseudomonas aeruginosa isolated from diseased fowls. Korean J. Vet. Res., 22, (2): $161-165$

Koneman, E.W.; Allen, S.D.; Janda, W.M.; Schreckenberger, P.C. and Winn, W.C. (1997): Diagnostic Microbiology. $5^{\text {th }}$ Ed. Chapter 1. Philadelphia. Newyork.

Malorny, B.; Hoorfar, J.; Hugas, M.; Heuvelink, A.; Fach, P.; Ellerbyoek, L.; Bunge, C.; Dorn, C. and Helmuth, $R$. (2003): Interlaboratory diagnostic accuracy of a Salmonella specific PCR-based method. Int. J. Food Microbiol., 89: 241-249.
Mena, K.D. and Gerba, C.P. (2009): Risk Assessment of Pseudomonas aeruginosa in water. Rev Environ Contam Toxicol, 201: 71115.

Middleton, J.R.; Fales, W.H.; Luby, C.D.; Landsay Oaks, J.; Susan Sanchez; Kinyon, J.M.; Wu, C.C.; Maddox, C.W. and Hartmann, F. (2005): Surveillance of Staphylococcus aureus in veterinary teaching hospitals. J. Clin. Microbiol., 43(6). 2916-2919

Mohamed, H.A.E.H. (2004): Some studies on Pseudomonas species in chicken embryos and broilers in assiut governorate. Assiut Univ Bull Environ Res, 7(1): 23-30.

Mrden, M.; Velhner, M.; Kovincic, I. and Gagic, M. (1988): Prevalence and the results of experimentally induced Pseudomoniasis in chicks. Peradarstovo, 23 (10): 295 - 298.

Nikbin, V.; Aslani, M.; Sharafi, Z.; Hashemipour, M.; Shahcheraghi, $F$. and Ebrahimipour, $G$. (2012): Molecular identification and detection of virulence genes among Pseudomonas aeruginosa isolated from different infectious origins. Iran J. Microbiol., 4: 118-123.

Quinn, J.P. (1992): Intrinsic antibiotic resistance in Pseudomonas aeruginosa. In: Galli, E., Silver, S. and Witholt, B. (eds). Pseudomonas. Molecular Biology and Biotechnology. American Society for Microbiology, Washington, D.C.

Saad, F.E.; Youssef, Y.I. And Awaad, M.H. (1981): Effect of $P$. aeruginosa on chicken embryos. Vet. Med. J. Cairo Univer., (29): 129 - 133.

Shukla, S. and Mishra, P. (2015): Pseudomonas aeruginosa Infection in Broiler Chicks in Jabalpur. International J Ext Res., 6:37-39.

Tamer, A.Ü.; Uçar.; Ünver, E.; Karaboz, I.; Bursalıoğlu, M. and Ve Oğultekin, R. (1989): Mikrobiyoloji Laboratuvar Klavuzu, 3.bask1, Ege Ün.Fen Fak Teksirler Serisi, No: 55, Bornova, 260.

Walker, S.E.; Sander, J.E.; Cline, J.L. and Helton, J.S. (2002): Characterization of Pseudomonas aeruginosa isolates associated with mortality in broiler chicks. Avian Dis, 46 (4): 10451050

Whittam, T.S. and Wilson, R.A. (1988): Genetic relationships among pathogenic strains of avian Escherichia coli. Infect. Immun. 56, 2458-2466

Xu, J.; Moore, J.E.; Murphy, P.G.; Millar, B.C. and Elborn, J.S. (2004): Early detection of Pseudomonas aeruginosa - comparison of conventional versus molecular (PCR) detection directly from adult patients with cystic fibrosis (CF). Annals of Clinical Microbiology and Antimicrobials, 3: 21.

Younes, T.; Youssef, H.; Abd AlKarim, S. and Hassanein, K. (1990): Epidemiologically Studies of $P$. aeruginosa in chickens, fish and human. Assiut, Vet. Med. J., 23 (45): 48-56. 


$$
\begin{aligned}
& \text { مدى الانتثار والضراوة والحساسية للمضادات الحيوية لميكروب السودوموناس } \\
& \text { ايروجينوزا المعزول من الاجاج المريض المئي }
\end{aligned}
$$

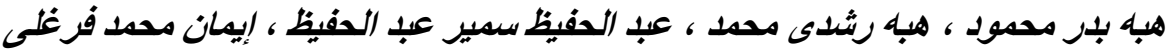

E-mail: drheba_badr@yahoo.com

Assiut University web-site: www.aun.edu.eg

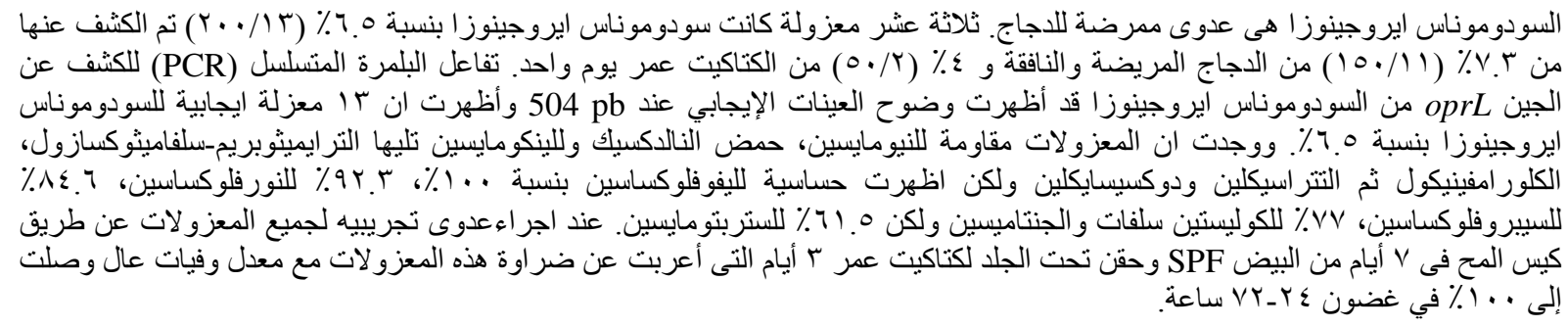

